\title{
The Students Value Attitude to Healthy Lifestyle
}

\author{
Marina Anatolevna Mefodeva \\ Senior Lecturer, \\ English Language Department for Social and Humanitarian Sphere, \\ The Institute of International Relations, \\ Kazan Federal University, Kazan, Russia \\ Gulnara Firdusovna Valieva \\ Senior Lecturer, \\ Department of Foreign Languages for \\ Physics, Mathematics and Information Technologies, \\ The Institute of International Relations, \\ Kazan Federal University, Kazan, Russia
}

Doi: 10.36941/jesr-2019-0009

\begin{abstract}
The relevance of the investigated problem is caused by the increased attention to the issues of a healthy lifestyle among students in Russia. Promotion of a healthy lifestyle, taking into account the individual interests and preferences of students can be embodied not only in the class but also in the framework of elective programs and courses, that are targeted on a healthy lifestyle. The authors reveal approaches, principles and pedagogical conditions for having a healthy lifestyle in the framework of training in educational institutions. The issues of bad habits influence the development and formation of a value attitude to a healthy lifestyle are considered.
\end{abstract}

Keywords: Healthy Lifestyle, Ecological Health, Bad Habits, Smoking, Alcoholism, Drug Addiction, Sport

\section{Introduction}

Creation of favorable conditions for the students' health strengthening and the formation of a culture of a healthy lifestyle is one of the main tasks of the education system in Russia. Promotion of a healthy lifestyle considering students' individual interests and preferences can be carried out not only at school classes but also in the framework of elective programs and courses, that are focused on having a healthy lifestyle. Scientists are concerned about the components of the "Healthy lifestyle" concept. They are all of the opinions that this term is of a multidisciplinary nature, and its various aspects are considered by a number of disciplines like physiology, anatomy, cultural studies, pedagogy, anthropology, history, geography, ecology, biology, computer science and so on (Blagush, 2012; Fakhrutdinova, 2013; Gordeeva, 2017; Khalikova, 2016; Zhiratkova, 2018). In short, this concept is extremely multifaceted, and it is so voluminous in content being rather relevant nowadays so, no doubt, that some works can be devoted to its structure only. Accordingly, without going into detail on its content, one can say that a healthy lifestyle is a responsible activity aimed at maintaining one's health through physical activity, refusal of bad habits, proper nutrition and the desire to maintain environmental balance.

The aim of our work is to study the approaches, principles and pedagogical conditions for having a healthy lifestyle in the framework of training in educational institutions, as well as the interest of the state in the development of a strong healthy nation. 


\section{Methods}

The health of the Russian population is currently in critical condition. The deterioration of the environmental background, the spread of such negative factors as alcoholism, smoking, drug addiction raises the issue of the physical health of the younger generation. It should be noted the high death rate of young people from external causes, namely $70 \%$ of young men and more than $50 \%$ of women die from injuries, accidents, suicides, alcohol and drug poisoning (Zhiratkova, 2018). The general morbidity rate of the younger generation at the age of 15-17 in 2014-2015 was characterized by the following indicators in the context of Federal districts: a high morbidity rate of young people was peculiar for the Volga and Central Federal districts. The far Eastern and Crimean Federal districts were the most resistant to diseases. Young people are quite confident in putting health in the first place in the hierarchy of life values and priorities, but at the same time, as sociological studies show, they do not take proper measures to preserve it. According to UN estimates, in 2017 Russia ranked 125th in life expectancy that is women's lifetime was 77.4 years old, and men's - 67.5 (Zhiratkova, 2018; Sazesh \& Siadat, 2018).

Despite the generally accepted idea that the way of life depends directly on the individual and no one has the right to interfere with the private life of citizens of a democratic state one thing remains important, namely the indirect influence through the processes that take place in society as a whole, mechanisms of social advertising and technology of children and youth involvement into activity which lays a solid foundation into the system of values in the learning process. It is in this period, under the influence of mentors, that possible qualitative shift in ideas about the quality of life can take place (Barhukov, 2013; Shchepkina, 2016).

At all stages of training, the presence of a mentor allows not only to form an idea of what is good or bad, but also to instill in students' habits of a healthy lifestyle (Verhoshansky, 2015; Santana et al., 2017). Thus, the presence of a mentor is considered to be the most important condition for the formation of healthy lifestyle value but not only at the micro level, at the level of personality, but also at the macro level that is the level of surrounding community. The next condition is the organization of the appropriate environment within the educational institution, and finally, the third condition - simultaneous use of the knowledge component integrated into the program and individual courses of the educational institution, and the active component that is the organization of extracurricular educational work. As a part of the teaching of the discipline, it is important to pay special attention to the advantages of proper, healthy lifestyle and to the disadvantages of the opposite process. It is important, as we see it, the direction of the special attention to the understanding of the positive impact of sport, nutrition, diet and the negative impact of bad habits (Grinchenko, 2000; Kora, 2015; Tejeda \& Dominguez, 2019).

Within the framework of the study of humanities (history, social science, literature, etc.), a relational component is formed, while studying subjects of natural science (biology, geography, medicine, etc.) - knowledge component, and during extracurricular activities and on PE classes behavioral component. All these subjects can reveal the harmful sides of these or those habits, without saying about addictions, as well as their impact on the body and the consequences from the physiological side.

The time that a child spends at school is a unique period that allows teachers to use both verbal methods (description, persuasion), visual methods (visualization), and active methods (hiking, competitions, training, walks). Various kinds of charts, tables, presentations, videos, films that are focused on a healthy lifestyle allow to give the low-down on the studied module from the biological and physiological points of view. Even the hardest students will not be able to deny the harmful effect of drugs, if a film with a detailed description and visuals of the processes that occur in the body of the drug addict is shown to them. In such cases, students will have to face a cruel and shocking reality, however, scientists are convinced all these means help to get good results.

As part of the organization of extracurricular work, thematic weeks dedicated to the promotion of a healthy lifestyle can be held. It should be noted that in forming the student's readiness to a healthy lifestyle the main pedagogical principle that is used here is systemacity. All the activities and events included in this work are aimed at providing students with knowledge and skills aimed at maintaining their health and having a healthy lifestyle (Glukhov, 2009). 
The next principle that needs special attention is sequence. The thing is teachers start forming the ideas about healthy lifestyle when a child goes to a kindergarten and continue this activity up to the time when children leave school. High school students are actively involved in activities aimed at keeping their health. Besides they should give their experience and knowledge to younger children, being a role model for them.

Realizing the importance of the nation's health for its further prosperity, the state pursues a strict policy aimed at reducing the risks of addiction to harmful habits of the younger generation. At present, the government and public organizations have already developed a large number of state projects, programs the goal of which is the active construction of sports and recreation complexes in Russia and even in its most remote regions. All the rural schools are equipped with the simplest sports equipment and playgrounds, which proves the state's interest in maintaining a healthy nation.

More responsibility is placed on political leaders and members of the public. They should become role models for students and show young people their interest and concern in improving society. Factors that can inspire this concern can be various meetings, discussions, press conferences which can help both sides to understand each other and coordinate the activities of an educational institution and a local (district) administration. Representatives of the public health service and health authorities can become participants in the process of forming a value attitude of young people to a healthy lifestyle. However, it is a prospect of talks and there is still much to do in this sphere (Babushkin, 2010; Fakhrutdinova, 2013; Shchepkina, 2016; Karimi Zarchi et al, 2016).

An important aspect of education of the youth in the context of globalization is the issue of intercultural ties. Here the Russian scientists argue about a positive or negative impact of the Westernisation process on the values of young people who live in an era of information globalization and multiculturalism. Obviously, the younger generation is obsessed with electronic gadgets, video and online games that have penetrated into our lives. Modern children are much more interested in playing computer games than doing sport or playing football with friends.

However, there is another side of influence. There are modern trends that have also come to Russia from outside, which have both pros and cons, namely diet, culture, fitness clubs, "beautiful" and "fashionable" sport. But to find a balance between the prosaic combination of good and bad each individual has to do on their own, as well as to seek harmony in the relationship between his spiritual and physical body. In dealing with this problem one can consider only himself (Mihajlova, 2016; Ibragimova, 2016).

The use of an integrated approach to education in the process of preparing students for life in society implies an aspect of ecological health that affects human health in general. It is the ecological situation and its development towards improvement or deterioration that allows remaining in disbalance or in balance with ourselves and the environment. The understanding of this aspect of human activity is the basis of the modern value attitude to a healthy lifestyle (Kasimova, 2016).

\section{Results and Conclusion}

The preservation and maintenance of the nation's health are seen by the authors of the study as a complex and difficult task. Modern technologies of education which are based on the concepts of activity and systematic approaches underlie its solution (Babushkin, 2010). But at the same time, its solution is complicated by the existing tension in society, economic heterogeneity, the difficult situation in today's society, etc. As research shows, among the bad habits, smoking occupies a leading place. Russia is in the top 10 most smoking countries (Holtzman, 2017). The most common reasons why students started smokings were stress or personal problems (16.0\%), curiosity (12.5), the influence of friends (10.7\%) (Zhiratkova, 2018).

Drug addiction and alcoholism pose the greatest threat to the health of the population and the socio-economic situation in Russia. In recent years, there has been a positive trend in Russia to reduce alcohol consumption per capita. Experts confirm that the Russians have learned to have a good time without alcohol, for example, doing sport.

Independent experts and scientists from different countries have found that human health is 
$50-55 \%$ dependent on conditions and lifestyle, $20-25 \%$ - on environmental factors, up to $20 \%$ on genetic factors and only 8-10 \% - on the state of health care (Zhiratkova, 2018).

The understanding of the importance of healthy lifestyle, the "vogue" to abandon bad habits, the growing patriotism of the population and the corresponding understanding of the government of the need to maintain a healthy and strong nation allow to talk about the possibility of positive dynamics in the formation of a value attitude to a healthy lifestyle among students. In recent years there has been a positive trend in promoting a healthy lifestyle among students in Russia. Scientists are sure that it is through the formation of a fashion for a healthy lifestyle that students can be protected from negative consequences in the transition from the stage of youth to adulthood. Health is not only a personal value but also public one: a sick population cannot become a reliable support of the state. This is especially true for students who are a key indicator of the well-being of society and the country as a whole.

\section{Aknowledgements}

The work is performed according to the Russian Government Program of Competitive Growth of Kazan Federal University.

\section{References}

Babushkin, B. D. (2010). Psychological bases of formation of professional interest to pedagogical activity. Omsk: OGIFK.

Barhukov, I. S. (2013). Physical Education. Moscow: UNITY-DANA.

Biktagirova, G. (2016). Formation of university students' healthy lifestyle // International Journal of Environmental and Science Education, Vol. 11 (6). P. 1159-1166.

Blagush, P. (2012). On the theory of testing motor abilities. Moscow: FKiS.

Fakhrutdinova, E., Severyanov, O., Valeev, E. (2013). The Transformation of Educational Approaches at the Time of Social and Economic Changes // World Applied Sciences Journal. Economics, Management and Finance, 27(13), 15-19.

Glukhov, V. I. (2009). Physical culture in the formation of a healthy lifestyle. Kiev: Zdorovie.

Gordeeva, I. V. (2017). Contemporary state and problem of forming students' youth healthy lifestyle. Uchenye zapiski universiteta imeni P.F. Lesgafta, 11(153), 54-59

Grinchenko, N. A. (2000). Prevention of drug addiction (methodological recommendations for teachers). Elets: ESPI.

Holtzman, D. (2017). Public health social work: An uncertain future. American Journal of Public Health, 107(S3), S221-S222.

Ibragimova, T. G. (2016). Phatics - Actual problems of linguistics Uzbek research. UCT Journal of Social Sciences and Humanities Research, 4(2), 16-19.

Karimi Zarchi, S., Dehestani, M. A., \& Farimani, A. (2016). The relationship between the proportion of long-term debt to total assets and economic value throughout the life of the company. UCT Journal of Management and Accounting Studies, 4(2), 16-21.

Kasimova, R., Biktagirova, G. (2016). Formation of university students' healthy lifestyle. International Journal of Environmental and Science Education, 11(6), 1159-1166.

Khalikova, S. S. (2016). Formation of healthy lifestyle of student youth of higher educational institutions. Uchenye zapiski of PNU, 7(2), 157-162.

Kora, N. A., Shchepkina, N. K. (2015). Research of personal security of students in the conditions of threat of spread of drug addiction in the educational environment of higher education institution. Kazan pedagogical journal, 4-1, 24-26.

Mihajlova, S. V. et al. (2016). Evaluation of the health of modern students. Health and Education, 18(2), 494497.

Santana, L. F., dos Santos, L. F. C., Silva, T. S. C., Villar, V. B., Rocha, F. G., \& Gonçalves, V. (2017). Scrum as a Platform to Manage Students in Projects of Technological Development and Scientific Initiation: A Study Case Realized at UNIT/SE. Journal of Information Systems Engineering \& Management, 2(2), 7. https://doi.org/10.20897/jisem.201707

Sazesh, A., \& Siadat, S. A. (2018). The Relationship between Quantum Management and Organizational Agility in Ministry of Roads and Urban Development of Golestan Province, Iran. Dutch Journal of Finance and Management, 2(2), 51. https://doi.org/10.29333/djfm/5827 
Shchepkina, N. K., Andreichenko, A. O. (2016). Study of structural and substantial peculiarities of the student's social creativity. Bulletin of Amur State University, 72, 68-73.

Tejeda, S., \& Dominguez, A. (2019). Influence of Interactions in the Collaborative Solving of a Velocity Problem. International Electronic Journal of Mathematics Education, 14(1), 91-108. https://doi.org/10.12973/iejme/3979

Verhoshansky, U. V. (2015). Basics of special physical training of athletes. Moscow: FiS.

Zhiratkova, Zh. V., Petrova, T. E., Leontyeva, A. V. (2018). Promotion of a Healthy Lifestyle among Students (a Sociological Analysis). Regionology, 4(105), 784-797. 